\title{
Consumptive Hypothyroidism: T3 or Not T3, That Is the Question
}

\author{
Kevin Hess ${ }^{1}$, Soraya Bascoy ${ }^{1}$, James Lenhard ${ }^{2}$ \\ ${ }^{1}$ Department of Internal Medicine, Christiana Care, Newark, USA \\ ${ }^{2}$ Department of Endocrinology, Christiana Care, Newark, USA \\ Email: kevin.hess@christianacare.org
}

How to cite this paper: Hess, K., Bascoy, S. and Lenhard, J. (2021) Consumptive Hypothyroidism: T3 or Not T3, That Is the Question. Open Journal of Endocrine and Metabolic Diseases, 11, 165-169.

https://doi.org/10.4236/ojemd.2021.1110015

Received: July 19, 2021

Accepted: October 28, 2021

Published: October 31, 2021

Copyright $\odot 2021$ by author(s) and Scientific Research Publishing Inc. This work is licensed under the Creative Commons Attribution International License (CC BY 4.0).

http://creativecommons.org/licenses/by/4.0/

\begin{abstract}
Consumptive hypothyroidism is often the clinical condition that results from neoplasms producing their own selenodionases that convert $\mathrm{T} 4$ needed to be converted to active T3 into an active form of thyroid hormone, rT3. This often requires treatment with high doses of IV T4, with or without doses of T3 as well, until the neoplasm is treated. This principle is demonstrated in the below case of a $65 \mathrm{y} / \mathrm{o}$ female with medical history significant for Ia Kappa multiple myeloma, complete heart block s/p AICD placement, and papillary thyroid cancer status post thyroidectomy in 2020 , who had initially presented with persistent bone pain, progressive encephalopathy and failure to thrive with more than a $50 \mathrm{lb}$ weight loss over a few months. Labs on presentation were not remarkable for progression of her underlying multiple myeloma, however, she was found to have a new significantly elevated TSH. She underwent imaging with a CT chest, abdomen, and pelvis, which showed new hepatic lesions, subcutaneous nodules, and new pulmonary nodules with associated lymphadenopathy and a left-sided pleural effusion. CT-guided liver biopsy evinced a metastatic neuroendocrine carcinoma, further supported by an elevated calcitonin and chromogranin. She was treated with high dose IV $\mathrm{T} 4$ at $1.38 \mathrm{mcg} / \mathrm{kg}$ however continued to worsening thyroid function labs. She was then started on Liothyronine at $20 \mathrm{mcg}$ and subsequently improved. This patient's case illustrates the importance of considering consumptive hypothyroidism when thyroid profile abnormalities and symptoms of severe hypothyroidism are seen in the context of malignant neoplasms, and further illustrates the important of considering $\mathrm{T} 3$ as part of the treatment regimen when IV T4 is not resulting in improvement.
\end{abstract}

\section{Keywords}

Hypothyroidism, Consumptive Hypothyroidism, Neuroendocrine Tumors 


\section{Introduction}

Thyroid hormones are circulating hormones widely involved in the development and metabolic homeostasis in virtually all mammalian tissues [1]. There are numerous forms of thyroid hormones that circulate throughout the body, some of which are metabolically active (T3, T4), while others have minimal to no effect on metabolism (T2, rT3). The conversion between these various forms of thyroid hormone relies on a group of enzymes known as selenodeiodinases which either remove or rearrange the various iodine moieties within the thyroid hormone molecular backbone [2]. There are 3 types of deiodinases, designated D1, D2, and D3; D1 \& D2 help with activation and conversion of T4 to T3, while D3 inactivates $\mathrm{T} 4$ into $\mathrm{rT} 3$ and $\mathrm{T} 2$. The physiologic importance of D3 stems from the necessity of inactivating T4 when too much unbound T4 is circulating, however, there are increasing numbers of case reports evincing that different classes neoplasms will produce their own D3, resulting in a rare type of hypothyroidism known as "consumptive hypothyroidism" [1] [3]. This disease state results in T4 being consumed and inactivated to rT3. Because of the depletion of T4, case reports typically suggest treating with high doses of IV T4, with or without doses of T3 [4] [5]. The aforesaid, along with treatment of the underlying neoplasm, tends to result in resolution of the consumptive hypothyroidism. [4] [5]. In this case, we introduce a case in which a patient presents with signs and symptoms of consumptive hypothyroidism following the diagnosis of metastatic neuroendocrine malignancy.

\section{Case Description}

The patient is a 65 -year-old female with stage Ia Kappa multiple myeloma, complete heart block s/p AICD placement, and papillary thyroid cancer status post thyroidectomy in 2020 . On presentation to the ED, she had complaints of persistent bone pain, progressive encephalopathy and failure to thrive with more than a $50 \mathrm{lb}$ weight loss over a few months. Of note, while there had been concerns of progressive malignancy in the outpatient setting, she had struggled to obtain imaging for this, as she was unable to obtain an MRI due to her AICD or a PET scan due to difficulties with her insurance. On arrival, vital signs were stable, except for tachycardia to 106. Labs showed a $1.7 \mathrm{~g} / \mathrm{dL}$ IgA kappa monoclonal gammopathy with increased kappa lambda ratio and absolute Kappa level of only 22.1. IgA level was 1330 with suppressed IgG and IgM. Albumin, LDH and beta-2 microglobulin were normal. No evidence of new anemia, renal insufficiency or hypercalcemia was found. TSH, however, was $32.15 \mathrm{MIU} / \mathrm{L}$ and T4 was $1.1 \mathrm{ng} / \mathrm{dL}$.

Since her presentation was inconsistent with the progression of multiple myeloma alone, the patient underwent imaging with a CT chest, abdomen, and pelvis, which showed new hepatic lesions, subcutaneous nodules, and new pulmonary nodules with associated lymphadenopathy and a left-sided pleural effusion. CT-guided liver biopsy evinced a metastatic neuroendocrine carcinoma, further 
supported by an elevated calcitonin of $1693 \mathrm{ng} / \mathrm{mL}$ and a chromogranin of 892 $\mathrm{pg} / \mathrm{mL}$. She was initiated on the appropriate chemotherapy and started on 1.38 $\mathrm{mcg} / \mathrm{kg}$ of IV Levothyroxine for the hypothyroidism. Follow up thyroid function tests a week later showed an increasing TSH of $38.87 \mathrm{MIU} / \mathrm{L}$ with downtrending free $\mathrm{T} 4$ and $\mathrm{T} 3$ at $0.7 \mathrm{ng} / \mathrm{dL}$ and $0.2 \mathrm{ng} / \mathrm{mL}$, respectively.

In light of these findings, there was significant concern for consumptive hypothyroidism related to the newly diagnosed neuroendocrine tumor. The patient was thus started on Liothyronine $20 \mathrm{mcg}$. Her TSH improved to 19.1 and T3 improved to 1.3, with free T4 remaining at 0.7 after 3 days. The IV Levothyroxine was discontinued after one week and she was transitioned to her home regimen of levothyroxine, but continued on Liothyronine for another 2 weeks. Her TSH normalized to 0.38 , as did her T4 and T3 levels to 1.0 and 1.8 , respectively. Over this time course, she received 2 cycles of carboplatin and etoposide followed by GCS-F support, and was subsequently discharged, as her failure to thrive and mental status improved significantly after being treated for her new underlying malignancy and the consumptive hypothyroidism.

\section{Discussion}

Consumptive hypothyroidism, though a rare phenomenon associated with malignancy, has been described in association with certain tumors that produce ectopic type 3 deiodinases, which metabolizes T4 to reverse T3 and T3 to T2 in an excessive fashion. This has mostly been associated with vascular and fibrotic tumors, as well as gastrointestinal stromal tumors (GISTs) in adults, and seems to be otherwise more prevalent among pediatric patients, often situated in the context of congenital hypothyroidism. That being said, this rare and severe hypothyroidism is not confined to this specific population or classes of neoplasms. In all cases, the features are the same: there is a laboratory profile showing persistently elevated TSH with accompanying low T4 and T3 levels that initially worsen after the administration of synthetic thyroid hormones. Treatment has varied across different case reports depending on both neoplasm subtype and initial responsiveness, however, some researchers suggest that patients do well when IV Levothyroxine followed by Liothyronine is given if the patient does not improve, followed by appropriate treatment of the underlying neoplasm [6] [7] [8]. These patients were usually able to discontinue thyroid replacement once all of this was performed. If there is prior thyroid malignancy with total thyroidectomy, as seen in our patient, these patients do continue to require supplemental levothyroxine even after successful treatment of neuroendocrine carcinoma.

Perhaps most importantly, consumptive hypothyroidism should be considered when significant thyroid abnormalities are seen, especially if malignancy is co-occurring, as said malignancy could be responsible for ectopic type 3 deiodinases that deactivate T4 and T3. Additionally, since the diagnosis of this entity partially depends on treatment response, that resolution occurs when there is 
aggressive treatment of the thyroid dysfunction and the neoplasm in tandem should also clue in providers to this disorder.

\section{Conclusion}

This patient's case illustrates the importance of considering consumptive hypothyroidism when thyroid profile abnormalities and symptoms of severe hypothyroidism are seen in the context of malignant neoplasms. Treatment involves high levels of synthetic thyroid hormone and can often show worsening of lab values upon initial administration. This must be done in the context of co-treatment of the malignant neoplasm in order to address the underlying etiology.

\section{Acknowledgements}

Ethics and consent were obtained for participation. Patient consent was obtained for both write up and publication as well. Data and material was obtained via electronic medical record access. No funding was required for this study. We would like to thank the Christiana Care Health System for allowing the opportunity to evaluate and treat this patient as we did in the case depicted above.

\section{Conflicts of Interest}

The authors declare no conflicts of interest regarding the publication of this paper.

\section{References}

[1] Luongo, C., Trivisano, L., Alfano, F. and Salvatore, D. (2013) Type 3 Deiodinase and Consumptive Hypothyroidism: A Common Mechanism for a Rare Disease. Frontiers in Endocrinology, 4, 115. https://doi.org/10.3389/fendo.2013.00115

[2] Dentice, M., Marsili, A., Zavacki, A., Larsen, P.R. and Salvatore, D. (2013) The Deiodinases and the Control of Intracellular Thyroid Hormone Signaling during Cellular Differentiation. Biochimica et Biophysica Acta, 1830, 3937-3945. https://doi.org/10.1016/j.bbagen.2012.05.007

[3] Güven, A., Aygun, C., Ince, H., Aydin, M., Pinarli, F.G., Baysal, K., et al. (2005) Severe Hypothyroidism Caused by Hepatic Hemangioendothelioma in an Infant of a Diabetic Mother. Hormone Research in Paediatrics, 63, 86-89. https://doi.org/10.1159/000083879

[4] Mouat, F., Evans, H.M., Cutfield, W.S., Hofman, P.L. and Jefferies, C. (2008) Massive Hepatic Hemangioendothelioma and Consumptive Hypothyroidism. Journal of Pediatric Endocrinology and Metabolism, 21, 701-703. https://doi.org/10.1515/JPEM.2008.21.7.701

[5] Jassam, N., Visser, T.J., Brisco, T., Bathia, D., McClean, P. and Barth, J.H. (2011) Consumptive Hypothyroidism: A Case Report and Review of the Literature. Annals of Clinical Biochemistry, 48, 186-189. https://doi.org/10.1258/acb.2010.010170

[6] Huang, S.A., Fish, S.A., Dorfman, D.M., Salvatore, D., Kozakewich, H.P., Mandel, S.J., et al. (2002) A 21-Year-Old Woman with Consumptive Hypothyroidism Due to a Vascular Tumor Expressing Type 3 Iodothyronine Deiodinase. Journal of Clinical Endocrinology \& Metabolism, 87, 4457-4461. https://doi.org/10.1210/jc.2002-020627 
[7] Ruppe, M.D., Huang, S.A. and Jan de Beur, S.M. (2005) Consumptive Hypothyroidism Caused by Paraneoplastic Production of Type 3 Iodothyronine Deiodinase. Thyroid, 15, 1369-1372. https://doi.org/10.1089/thy.2005.15.1369

[8] Howard, D., La Rosa, F.G., Huang, S., Salvatore, D., Mulcahey, M., Sang-Lee, J., et al. (2011) Consumptive Hypothyroidism Resulting from Hepatic Vascular Tumors in an Athyreotic Adult. Journal of Clinical Endocrinology \& Metabolism, 96, 1966 1970. https://doi.org/10.1210/jc.2010-2104 